\title{
PD-1 Inhibitor-induced Gastroenterocolitis: A Mini Review
}

\author{
Phoenix D Bell and Aaron R Huber* \\ Department of Pathology, University of Rochester Medical Center, USA
}

\section{Introduction}

Programmed cell death protein 1 (PD-1) is a protein present on the surface of T lymphocytes. PD-1 binds to programmed death ligand 1 (PD-L1) and ligand 2 (PD-L2) on the surface of antigen presenting cells, which prevents cytotoxic $\mathrm{T}$ lymphocytes from recognizing selfantigens and thus, serves as an important protein in immune tolerance [1]. Recently, antibodies directed at the PD-1 signaling pathway (nivolumab and pembrolizumab), so-called "immune checkpoint inhibitors", have been approved by the Food and Drug administration for the treatment of advanced-stage malignancies [2]. Some tumors express PD-L1, which allows tumor cells to evade the T-cell mediated immune response and ultimately proliferate. PD-1 inhibitors prevent the interaction of PD-L1 with PD-1, thereby enabling cytotoxic T lymphocytes to fight tumor cells [3]. Unfortunately, these agents can also have autoimmune-related adverse events termed immune related adverse events (irAEs),' which have a propensity to affect the gastrointestinal tract, liver, lungs, and endocrine organs [4-7]. In fact, diarrhea is one of the most common side effects reported with PD- 1 inhibitor therapy, occurring in up to $20 \%$ of patients $[7,8]$. Two series $[9,10]$ have recently described the histopathologic features of colitis associated with PD-1 inhibitors and herein, we review the histopathologic features of PD-1 inhibitor colitis.

\section{Histopathologic features of PD-1 inhibitor colitis}

In the series from Gonzalez et al. [9], seventeen biopsies were from the colon. A majority of the colon specimens demonstrated neutrophilic cryptitis/abscesses (8/17, 47\%; Figure 1) and expansion of the lamina propria by a mononuclear infiltrate $(13 / 17,76 \%)$. Other common features included crypt architectural distortion (9/17, 53\%) and increased apoptosis (8/17, 47\%; Figure 2). Some cases showed features of ischemic colitis $(3 / 17,18 \%)$ or crypt rupture with associated histiocyte aggregates, which occasionally formed granulomata $(3 / 17$, $18 \%)$. A thickened subepithelial collagen table suggestive of collagenous colitis was seen in only one case (Figure 3 ) and has been reported once previously in the literature [11].

In the series from Chen et al. [10], two patterns of injury were described: 1) an active colitis with apoptosis pattern and 2) a lymphocytic colitis pattern. The active colitis pattern was the most common $(5 / 8,63 \%)$, which demonstrated active inflammation, neutrophilic crypt abscesses, increased crypt apoptosis, and crypt atrophy/dropout. The lymphocytic colitis pattern was less common $(3 / 8,37 \%)$ and showed increased intraepithelial lymphocytes in the surface epithelium, injury of the surface epithelium, and mononuclear expansion of the lamina propria. Interestingly, changes of chronic colitis mimicking inflammatory bowel disease, including basal plasmacytosis, mononuclear expansion of the lamina propria, and crypt architectural

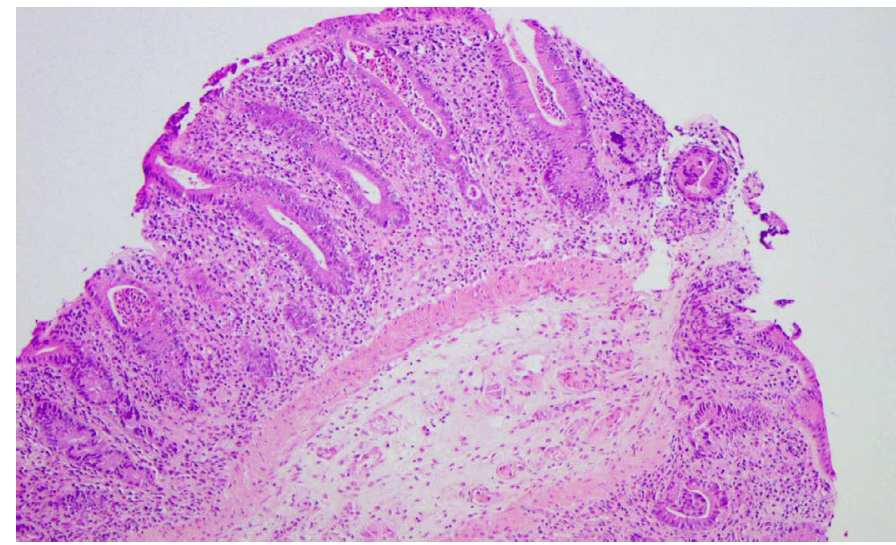

Figure 1. Colonic mucosa with active inflammation and crypt abscesses in a case of PD-1 inhibitor colitis (H\&E, original magnification x100)

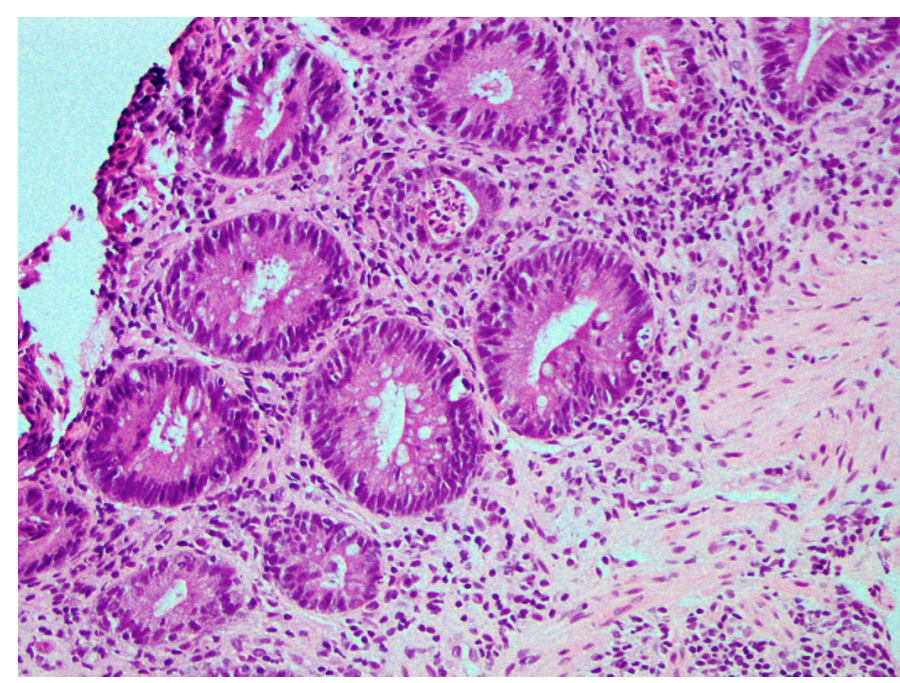

Figure 2. Colonic mucosa with active inflammation and crypt abscesses and increased crypt apoptotic bodies (active colitis with apoptosis pattern) in another case of PD-1 inhibitor colitis (H\&E, original magnification x200).

*Correspondence to: Aaron R. Huber, DO, Department of Pathology and Laboratory Medicine, University of Rochester Medical Center, 601 Elmwood Ave, Box 626 Rochester, NY 14642, USA, E-mail: aaron_huber@urmc.rochester.edu

Key words: PD-1 inhibitor, colitis, pembrolizumab, nivolumab

Received: July 21, 2019; Accepted: August 10, 2019; Published: August 14, 2019 


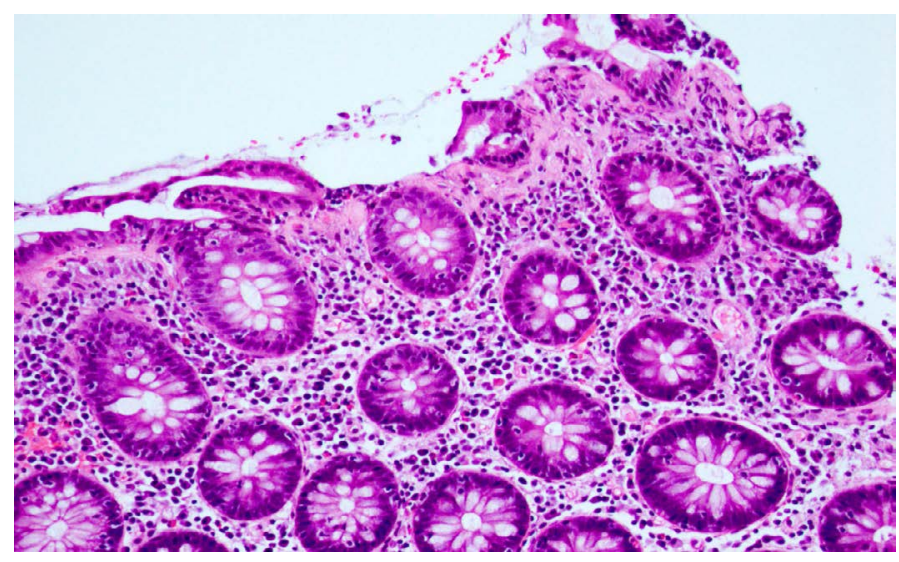

Figure 3. Colonic mucosa with subepithelial collagen thickening similar to collagenous colitis in another case of PD-1 inhibitor colitis (H\&E, original magnification x400).

distortion, may be seen in patients who experience recurrent PD-1 inhibitor colitis after restarting therapy, but are typically not present without re-challenge.

The histopathologic differential diagnosis should include several entities, based upon the pattern of injury. The finding of numerous apoptotic bodies raises the possibility of either graft-versus-host disease or mycophenolate mofetil-induced injury [12,13]. Graftversus-host disease rarely has abundant active inflammation, similar to that seen in PD-1 inhibitor colitis, while mycophenolate mofetil tends to have an inflammatory component that is rich in mucosal eosinophils and not neutrophils [12-14]. Ultimately, clinicopathologic correlation is required to differentiate these entities. If the pattern is active colitis with apoptosis, cytomegalovirus should be entertained, which can be excluded easily with an immunohistochemical stain for cytomegalovirus $[9,10]$. If the biopsies demonstrate the uncommon ischemic colitis-like pattern, then ischemic colitis from either vascular insufficiency or infection enters the differential diagnosis [9]. Rarely, the subepithelial collagen table may be thickened, mimicking collagenous colitis; however, more commonly, there is a lymphocytic colitis pattern. These findings raise the possibility of microscopic colitis, which also requires clinicopathologic correlation [9-11]. If there are chronic colitis-type changes, inflammatory bowel disease should be considered. Aside from crypt architectural distortion, these changes are uncommon outside the setting of recurrent PD-1 inhibitor colitis $[9,10]$. Crohn disease may enter the differential diagnosis in cases with crypt rupture and mucosal granulomata; however, other features of Crohn disease are usually not identified $[9,10]$.

\section{Conclusion}

With the advent of immunotherapy for cancer with "checkpoint inhibitors," it is important for clinicians and pathologists alike to be aware that these agents may induce immune-related adverse events such as colitis. From the two series describing the histopathologic features of PD-1 inhibitor colitis $[9,10]$ the most frequent findings are active inflammation, including crypt abscesses, expansion of the lamina propria, and increased apoptosis. Less common findings are lymphocytic colitis, collagenous colitis, ischemia-like colitis, or crypt rupture with histiocyte aggregates and/or granulomata $[9,10]$. As suggested by Gonzalez et al. [9], it may be best to refer to the histologic findings as "immunomodulatory gastroenterocolitis" as they are not specific and may be seen with other checkpoint inhibitors, such as the cytotoxic T lymphocyte antigen-4 (CTLA-4) inhibitor ipilimumab, which is well-known to cause colitis with active inflammation, cryptitis and crypt abscesses, and apoptosis $[15,16]$. It is imperative that pathologists recognize colitis in this setting so that appropriate treatment, including withdrawal of the PD-1 inhibitor and the administration of steroids, may be instituted $[17,18]$.

\section{References}

1. Keir ME, Butte MJ, Freeman GJ, Sharpe AH (2008) PD-1 and its ligands in tolerance and immunity. Annu Rev Immunol 26: 677-704. [Crossref]

2. Ascierto PA, Marincola FM (2015) 2015: The Year of Anti-PD-1/PD-L1s Against Melanoma and Beyond. EBioMedicine 2: 92-93. [Crossref]

3. McDermott DF, Atkins MB (2013) PD-1 as a potential target in cancer therapy. Cancer Med 2: 662-673. [Crossref]

4. Garon EB, Rizvi NA, Hui R, Leighl N, Balmanoukian AS, et al. (2015) Pembrolizumab for the treatment of non-small-cell lung cancer. N Engl J Med 372: 2018-2028. [Crossref]

5. Naidoo J, Page DB, Li BT, Connell LC, Schindler K, et al. (2015) Toxicities of the anti-PD-1 and anti-PD-L1 immune checkpoint antibodies. Ann Oncol 26: 2375-2391. [Crossref]

6. Champiat S, Lambotte O, Barreau E, Belkhir R, Berdelou A, et al. (2016) Management of immune checkpoint blockade dysimmune toxicities: a collaborative position paper. Ann Oncol 27: 559-574. [Crossref]

7. Topalian SL, Hodi FS, Brahmer JR, Gettinger SN, Smith DC, et al. (2012) Safety, activity, and immune correlates of anti-PD-1 antibody in cancer. $N$ Engl J Med 366 : 2443-2454. [Crossref]

8. Hamid O, Robert C, Daud A, Hodi FS, Hwu WJ, et al. (2013) Safety and tumor responses with lambrolizumab (anti-PD-1) in melanoma. $N$ Engl J Med 369: 134-144. [Crossref]

9. Gonzalez RS, Salaria SN, Bohannon CD, Huber AR, Feely MM, et al. (2017) PD-1 inhibitor gastroenterocolitis: case series and appraisal of "immunomodulatory gastroenterocolitis". Histopathology 70: 558-567. [Crossref]

10. Chen JH, Pezhouh MK, Lauwers GY, Masia R (2017) Histopathologic Features of Colitis Due to Immunotherapy With Anti-PD-1 Antibodies. Am J Surg Pathol 41: 643 654. [Crossref]

11. Baroudjian B, Lourenco N, Pages C, Chami I, Maillet M, et al. (2016) Anti-PD1induced collagenous colitis in a melanoma patient. Melanoma Res 26: 308-311. [Crossref]

12. Washington K, Jagasia M (2009) Pathology of graft-versus-host disease in the gastrointestinal tract. Hum Pathol 40: 909-917. [Crossref]

13. Selbst MK, Ahrens WA, Robert ME, Friedman A, Proctor DD, et al. (2009) Spectrum of histologic changes in colonic biopsies in patients treated with mycophenolate mofetil. Mod Pathol 22: 737-743. [Crossref]

14. Star KV, Ho VT, Wang HH, Odze RD (2013) Histologic features in colon biopsies can discriminate mycophenolate from GVHDinduced colitis. Am J Surg Pathol 37 1319-1328. [Crossref]

15. Gupta A, De Felice KM, Loftus EV Jr, Khanna S (2015) Systematic review: colitis associated with anti-CTLA-4 therapy. Aliment Pharmacol Ther 42: 406-417. [Crossref]

16. Verschuren EC, van den Eertwegh AJ, Wonders J, Slangen RM (2016) Clinical, endoscopic, and histologic characteristics of ipilimumab-associated colitis. Clin Gastroenterol Hepatol 14: 836-842. [Crossref]

17. Allison JP (2015) Immune checkpoint blockade in cancer therapy: the 2015 LaskerDeBakey Clinical Medical Research Award. JAMA 314: 1113-1114. [Crossref]

18. Okazaki T, Chikuma S, Iwai Y, Fagarasan S, Honjo T (2013) A rheostat for immune responses: the unique properties of PD-1 and their advantages for clinical application. Nat Immunol 14: 1212-1218. [Crossref]

Copyright: (C2019 Bell PD. This is an open-access article distributed under the terms of the Creative Commons Attribution License, which permits unrestricted use, distribution, and reproduction in any medium, provided the original author and source are credited. 